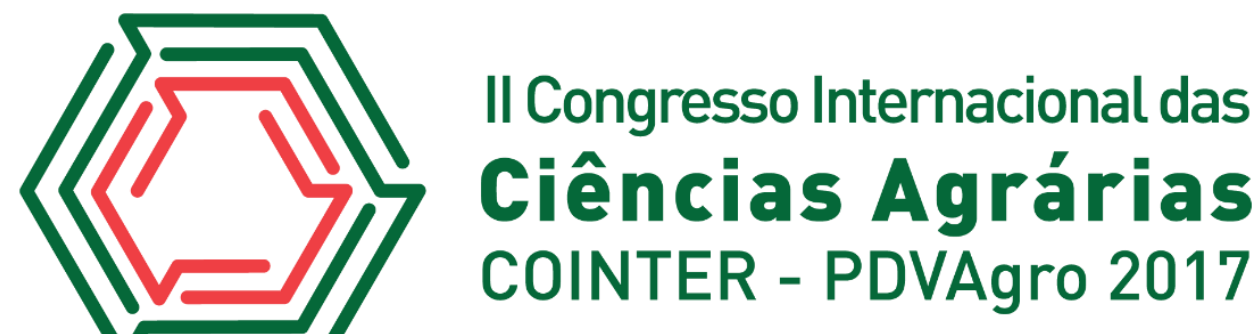

\section{DESENVOLVIMENTO INICIAL DE DUAS ESPÉCIES ARBÓREAS NATIVAS EM ÁREAS DEGRADADAS DA CAATINGA}

\author{
Apresentação: Pôster \\ Bruna Rafaella Ferreira da Silva ${ }^{1}$; Thalles Luiz Negreiros da Costa $^{2}$; Tatiane Kelly Barbosa \\ de Azevêdo ${ }^{3}$
}

\section{Introdução}

O Nordeste brasileiro, especificamente o seu semiárido, apresenta diversos problemas relacionados à degradação ambiental, provocados principalmente pela ação do homem, com ações relacionadas às atividades agrícolas, desmatamento para formação de pastagens e a retirada de lenha, além de seus animais em áreas de pastagens na caatinga (ARAÚJO FILHO e CARVALHO, 1996).

No ato da retirada total ou parcial da cobertura vegetal, bem como o uso inadequado dessas áreas, gera redução da biodiversidade local, podendo levar a degradação dos solos devido ao processo de erosão e o empobrecimento do mesmo através da retirada de partículas, podendo chegar a condições agravantes de desertificação (LIMA, 2004).

A recuperação de uma área degradada possui como objetivo trazê-la de volta ao sistema de produção, geralmente envolvendo a re-introdução de plantas na área, havendo mais chances de estabelecimento das espécies que corresponderem ao tipo de formação florestal original local (ARAÚJO, 2010). Para recuperação dessas áreas degradadas há a necessidade de utilização de princípios ecológicos e de práticas silviculturais, em que necessita ser feito um estudo básico da área em que vai se trabalhar, fazendo também a descrição das espécies que serão utilizadas como modelo de recuperação, devendo ser utilizadas espécies de rápido crescimento e alto valor econômico (LIMA, 2004).

Diante do exposto, o objetivo deste trabalho foi comparar o desenvolvimento inicial das espécies Enterolobium contortisiliquum e Dipteryx odorata em área degradada localizada no município de Currais Novos - RN.

\footnotetext{
${ }^{1}$ Engenharia Florestal, Universidade Federal do Rio Grande do Norte, brunarafaellaf@hotmail.com

2 Engenharia Florestal, Universidade Federal do Rio Grande do Norte, thallesengflorest@gmail.com

${ }^{3}$ Docente do curso de Engenharia Florestal, Universidade Federal do Rio Grande do Norte, tatianekellyengenheira@hotmail.com
} 


\section{Fundamentação Teórica}

A espécie Enterolobium contortisiliquum (Vell.) Morong. é popularmente conhecida como tamboril, é uma espécie da família Fabaceae, sendo uma planta que se encontra distribuída em todo o país, do nordeste ao sul, nas florestas ripárias e semidecíduas da caatinga, além de poder ser utilizada para recuperação de áreas degradadas de preservação permanente, principalmente devido ao seu rápido crescimento (LORENZI, 2002;) e também em reflorestamentos mistos (Durigan et al., 2002).

A espécie Dipteryx odorata (Aubl.) Willd,, pertencente à família Fabaceae, é conhecida popularmente como cumaru, e é uma espécie arbórea de grande porte, atingindo até $30 \mathrm{~m}$ de altura na floresta primária, porém de porte mais baixo quando cultivada ou em florestas secundárias (Loureiro et al., 1979; Revilla, 2000). Esta espécie é tida como importante para reflorestamentos, frutificando precocemente aos quatro anos de idade (PINTO et al., 2008).

\section{Metodologia}

O experimento foi conduzido no assentamento Trangola, localizado no município de Currais Nosso, região seridó do Rio Grande do Norte. Segundo a Köppen e Geiger a classificação do clima é BSh, com temperatura média anual de $25.9^{\circ} \mathrm{C}$ e média anual de pluviosidade de $528 \mathrm{~mm}$.

As mudas de ambas as espécies foram produzidas no viveiro de fruticultura da Escola Agrícola de Jundiaí (EAJ), pertencente à Universidade Federal do Rio Grande do Norte, localizado no município de Macaíba-RN. As mudas permaneceram no viveiro por 45 dias, sendo 30 dias destes sob sombrite e irrigação diária, e nos 15 dias finais foi realizado o processo de rustificação, em que as mudas foram expostas a pleno sol, além de receber irrigação apenas em dias alternados. O substrato utilizado foi areia peneirada + esterco bovino, na proporção 2:1 (v/v).

Foram utilizadas duas espécies nativas, sendo elas a Enterolobium contortisiliquum (Vell.) (tamboril) e Dipteryx odorata (Aublet.) Willd. (cumarú). O recipiente utilizado foi saco de polietileno de $30 \mathrm{~cm}$ de altura (volume médio: $1960 \mathrm{~cm}^{3}$ ). O plantio foi realizado em abril de 2017, com espaçamento de $3 \mathrm{~m}$ x $2 \mathrm{~m}$, e utilizado hidrogel de fundação.

Durante o período de 30 dias, as mudas foram irrigadas duas vezes por semana, com intuito de favorecer a relação raiz/solo durante a fase inicial. Todos os indivíduos foram plaqueados e mensurados nas variáveis altura $(\mathrm{H})$ e diametro na base (DNB) uma vez por mês. O crescimento médio das mudas das espécies florestais foi calculado pela diferença do valor final e inicial de altura e diâmetro na base. 


\section{Resultados e Discussões}

Durante o período de abril a agosto de 2017, constatou-se que as espécies Enterolobium contortisiliquumm e Dipteryx odorata obtiveram 100\% de sobrevivência, podendo estar relacionado com o uso do hidrogel de fundação nas covas em que as mudas foram plantadas, além da irrigação realizada duas vezes por semana no primeiro mês, coincidindo com o início do período chuvoso da região. Contudo, segundo Cromberg e Bovi (1992) puderam constatar em seus estudos, este índice pode se alterar com o passar do tempo, visto que o reflorestamento ainda não passou pela fase crítica, no qual necessitará de maiores quantidades de nutrientes e água. De acordo com Moura (2008) a fertilidade do solo, a compactação e principalmente a chuva são variáveis que podem afetar no comportamento das mudas em campo.

Quanto a análise do desenvolvimento inicial das espécies em campo observa-se na Figura 1 e 2, a média das alturas $(\mathrm{H})$ e a média dos diâmetros na base (DNB), respectivamente, durante o período de 5 meses.

Figura 1- Médias das alturas $(\mathrm{H})$ das espécies Enterolobium contortisiliquumm e Dipteryx odorata avaliados durante o período de 5 meses no Assentamento Trangola em Currais Novos - RN. Fonte: Própria.

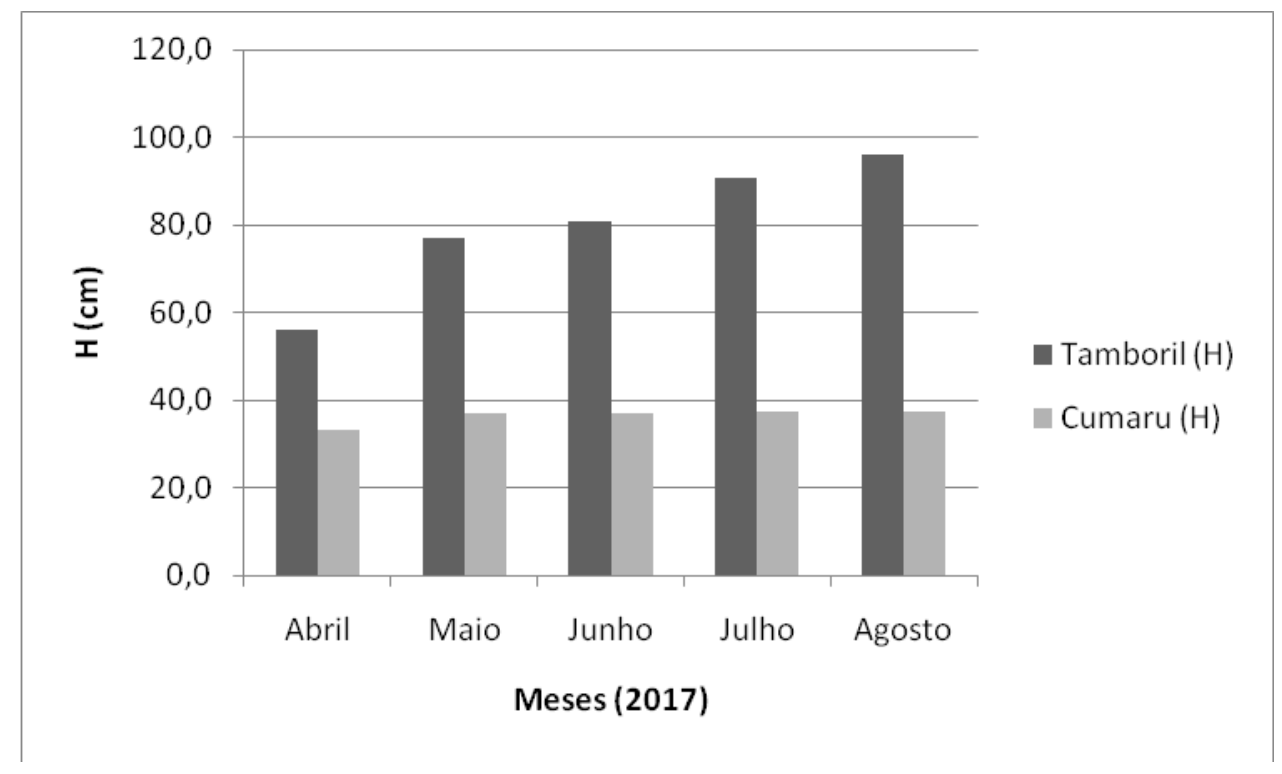

Na Figura 1 e 2 é possível visualizar que a espécie $E$. contortisiliquumm obteve um melhor desenvolvimento, quando comparada à $D$. odorata. Este comportamento pode estar relacionado ao fato de que a espécie E. contortisiliquumm é pioneira, desenvolvendo-se de melhor forma quando recebem sol pleno, enquanto que a $D$. odorata é uma espécie não pioneira, e Budowski (1965) afirma que espécies não pioneiras possuem melhor crescimento em ambientes sombreados. Gonçalves et al. (2005) e Couto (2014) constataram em seus trabalhos que há uma maior média de 
altura em espécies pioneiras e menor nas não pioneiras.

Figura 2 - Médias de Diâmetro na Base (DNB) das espécies Enterolobium contortisiliquumm e Dipteryx odorata avaliados durante o período de 5 meses no Assentamento Trangola em Currais Novos - RN. Fonte: Própria.

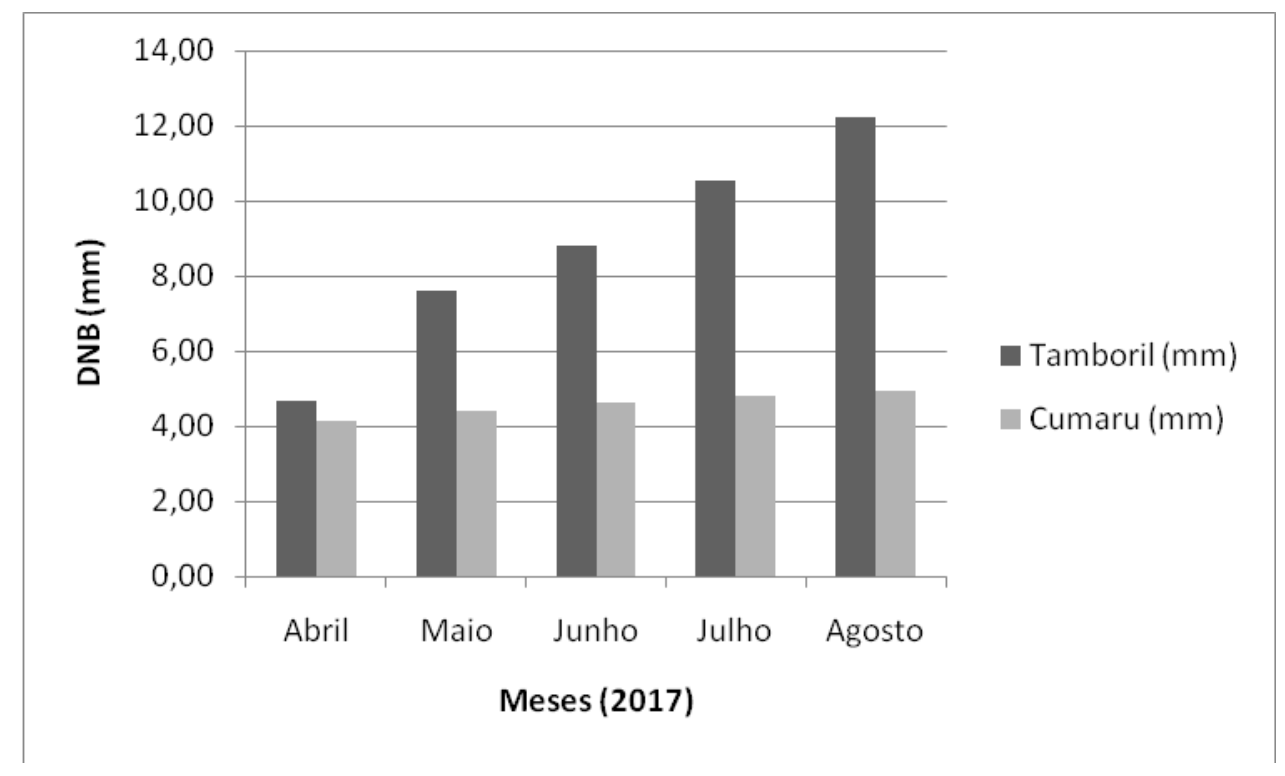

Na Tabela 3, é possivel observar o crescimento médio em diâmetro na base (DNB) e em altura $(\mathrm{H})$, para as duas espécies utilizadas neste estudo. $\mathrm{O}$ crescimento médio em diâmetro para a espécie Enterolobium contortisiliquum $(1,14 \mathrm{~mm})$ foi superior ao da espécie Dipteryx odorata $(0,18 \mathrm{~mm})$. O mesmo ocorreu com o crescimento em altura, $0,60 \mathrm{~cm}$ na E. contortisiliquum e 0,12 cm na D. odorata. Foram encontrados por Gonçalves et al. (2005) também valores superiores na taxa de crescimento de espécies pioneiras.

Figura 3- Média e desvio padrão (DesvPad) do crescimento médio das espécies Enterolobium contortisiliquumm e Dipteryx odorata para as variáveis diâmetro na base (DNB) e altura (H) no período de 5 meses no Assentamento Trangola, em Currais Novos - RN

\begin{tabular}{cccc}
\hline & & \multicolumn{2}{c}{ Crescimento Médio } \\
\hline & Espécie & $\mathrm{H}(\mathrm{cm})$ & DNB (mm) \\
\hline Enterolobium & Média & 0,60 & 1,14 \\
contortisiliquum & DesvPad & 15,40 & 2,88 \\
Dipteryx & Média & 0,12 & 0,18 \\
odorata & DesvPad & 1,83 & 0,33 \\
\hline
\end{tabular}

\section{Conclusões}

A espécie Enterolobium contortisiliquum apresentou maior taxa de crescimento tanto para a altura $(\mathrm{H})$ como para diâmetro na base (DNB). 
Nos meses avaliados até o momento houve $100 \%$ de sobrevivência em campo das duas espécies utilizadas neste estudo.

\section{Referências}

ARAÚJO, J M. Crescimento inicial de três espécies arbóreas nativas em áreas degradadas da caatinga. 2010. 29 f. Monografia (Especialização) - Curso de Engenharia Florestal, Universidade Federal de Campina Grande, Patos - PB, 2010.

ARAÚJO FILHO, J.A; CARVALHO, F. C. de. Desenvolvimento sustentado da Caatinga. In: ALVAREZ V. (Eds.). O solo nos grandes domínios morfoclimáticos do Brasil e o desenvolvimento sustentado. Viçosa: SBCS: 1996. p.125-133.

BUDOWSKI, G. N. Distribution of tropical American rain forest species in the light of succession processes. Turrialba, 15 (1) 40-2, 1965.

COUTO, G. M. Modelos de recuperação florestal em áreas ciliares no rio tracunhaém-pe. 2014. 87f. Tese (Dutorado em Ciências Florestais). Departamento de Engenharia Florestal, Universidade Federal Rural de Pernambuco. Recife, PE.

CROMBERG, V. U.; BOVI, M. L. A. Possibilidades do uso do palmiteiro (Euterpe edulis Mart) na recuperação de áreas degradadas de mineração. Revista do Instituto Florestal, São Paulo, v. 4, p. 339-648, 1992.

DURIGAN, G.; NISHIKAWA, D.L.L.; ROCHA, E.; SILVEIRA, E.R. da; PULITANO, F.M.; REGALADO, L.B.; CARVALHAES, M.A.; PARANAGUÁ, P.A.; RANIERI, V.E.L. Caracterização de uma vegetação de cerrado no município de Brotas, SP, Brasil. Acta Botanica Brasilica, v.16, n.3, p.251-262, 2002.

GONÇALVES, R. M. G. et al. Aplicação de modelo de revegetação em áreas degradadas, visando à restauração ecológica da microbacia do córrego da Fazenda Itaqui, no município de Santa Gertrudes, SP. Revista do Instituto Florestal, São Paulo, v. 17, n. 1, p. 73-95, 2005.

LIMA, P. C. F. Áreas degradadas: métodos de recuperação no semi-árido brasileiro. In: XXVII Reunião Nordestina de Botânica, 2004.

LORENZI, H. Árvores brasileiras: Manual de identificação e cultivo de plantas arbóreas nativas do brasil. 4.ed. Nova Odessa: Instituto Plantarum, 2002. 384p.

LOUREIRO, A. A. SILVA, M.F.; ALENCAR, J.C. 1979. Essências madeireiras da Amazônia. INPA, Manaus. 187 pp.

MOURA, A. C. C. Recuperação de áreas degradadas no Ribeirão do Gama o envolvimento da comunidade do núcleo hortícola de Vargem Bonita, DF. 2008. 125 f. Dissertação (Mestrado em Engenharia Florestal), Universidade de Brasília. Brasília

PINTO, A. M.; MOREllATO, L. P. C.; BARBOSA, A. P. Fenologia reprodutiva de Dipteryx odorata (Aubl.) Willd (Fabaceae) em duas áreas de floresta na Amazônia Central. Acta Amazonica, v. 38, n. 4, p.643-650, 2008.

REVILLA, J. 2000. Plantas da Amazônia: oportunidades econômicas e sustentáveis. SEBRAE/AM. 1. ed. Programa de Desenvolvimento Empresarial e Tecnológico, Manaus. 405p. 